\title{
Hidden patterns of play interaction in soccer using SOF-CODER
}

\author{
GUDBERG K. JONSSON \\ University of Iceland, Reykjavík, Iceland \\ and University of Aberdeen, Aberdeen, Scotland \\ M. TERESA ANGUERA, ÁNGEL BLANCO-VILLASEÑOR and JOSÉ LUIS LOSADA \\ University of Barcelona, Barcelona, Spain \\ ANTONIO HERNÁNDEZ-MENDO \\ University of Málaga, Málaga, Spain \\ TONI ARDÁ \\ University of A Coruña, A Coruña, Spain \\ OLEGUER CAMERINO \\ University of Lleida, Lleida, Spain \\ and \\ JULEN CASTELLANO \\ University of the Basque Country, Vitoria, Spain
}

\begin{abstract}
Traditional methods for quantifying sport performances are limited in their capacity to describe the complex interactions of events that occur within a performance over time. The following article outlines a new approach to the study of actions between players in team sports-mainly, soccer. Since the observational design is nomothetic, point, and multidimensional, an observational and data-collecting instrument has been developed. The instrument is mixed and combines a field format with a category system for game events, as well as an ad hoc instrument that considers the game actions of one or both teams, each recorded according to the same criteria. The article also outlines a new approach to the analysis of time-based event records-in this case, sports performance-known as T-pattern detection. The relevant elements of the T-pattern detection process are explained, and exemplar data from analyses of soccer matches are presented to highlight the potential of this form of data analysis. The results suggest that it is possible to identify new kinds of profiles for both individuals and teams on the basis of observational criteria and a further analysis of temporal behavioral patterns detected within the performances.
\end{abstract}

As the game of soccer has evolved, so have the methods of analyzing performance developed from the simple use of hand notation tracking of players' movements on scale plans of pitches (Bloomfield, Jonsson, Polman, Houlahan, $\&$ O'Donoghue, 2005) to the current utilization of video recordings and computerized analyses (Borrie, Jonsson, \& Magnusson, 2002).

In the field of sport research, there is a growing need for rigorous analysis of data, particularly in terms of identifying the sources of variability resulting from method-

We gratefully acknowledge the support of the Spanish government project Innovaciones en la Evaluación de Contextos Naturales: Aplicaciones al Ámbito del Deporte (Dirección General de Investigación, Ministerio de Ciencia y Tecnología; Grant BSO2001-3368). Correspondence concerning this article should be addressed to G. K. Jonsson, Human Behavior Laboratory, University of Iceland, Skipholt 50, IS-105 Reykjavik, Iceland (e-mail: gjonsson@hi.is). ological issues - for example, those caused by the varying methods of data collection used in studies, the lack of standardized approaches, and especially, the considerable differences in the approaches used to classify motion.

Traditional methods of analysis have used frequency of event occurrence as their index of performance-for example, recording the number of passes made from particular zones or how many times a team makes an error. However, if one accepts that sport performance consists of a complex series of interrelationships between a wide array of performance variables, simple frequency data can provide only a relatively superficial view of performance. There is thus a growing demand for data analysis methods or techniques that can generate more complete and, therefore, more complex quantitative representations of performance.

Nevertheless, traditional frequency analyses of performance have provided, and will continue to provide, valu- 
Table 1

Matches Recorded

\begin{tabular}{cllc}
\hline Place & Result & \multicolumn{1}{c}{ Teams } & Data Rows in Record File \\
\hline Home & Won & FCB-Racing & 426 \\
& Draw & FCB-Betis & 338 \\
& Lost & FCB-Deportivo & 682 \\
Away & Won & Las Palmas-FCB & 483 \\
& Draw & Numancia-FCB & 802 \\
& Lost & Athletic Bilbao-FCB & 403 \\
\hline
\end{tabular}

Note-FCB, Barcelona Football Club.

able information that coaches and performers can use to enhance the coaching process. Thus, the present article does not seek to argue that an analysis of temporal structure is better than other approaches in sport research but merely that it provides an additional and fresh perspective for performance analysts to consider and use, given that the game is transcribed with appropriately developed instruments.

In light of the above, the purpose of this article is to introduce and explain a data collection and analysis method that can be used to examine temporal structure in sport performance. Special attention is paid to the observational design embedded in the SOF-CODER software, which was developed for the study of the hidden structures underlying the interactive situation in a game of soccer, although it is also applicable to other team sports in which there are social interactions between players. The authors are concerned with the way in which temporal patterns are able to reveal those aspects of play interaction that are not immediately observable. The present view is that every interactive flow is governed by behavioral structures of varying stability that can be discovered and visualized through the detection of various kinds of temporal patterns-here, T-patterns (Magnusson, 1996, 2000).
Of course, social interaction is a very complex phenomenon, and the assumptions underlying its study are a starting point for research into social relationships, although there is no unified theory for the study of such processes. The most important of these are the inevitable multiplicity of the individuals involved, the diversity of existing interactive structures, the effect of context and interactive content, and both inter- and intrasession permanence and changeability, among many others. The study of social interaction is, thus, undoubtedly difficult from a methodological point of view, and in this regard, the contribution of observational methodology has proved decisive, whatever the situation (Anguera, 2003, 2005; Carletta et al., 2003).

Many specific issues can be addressed through the study of social interaction, since the latter constitutes an extensive field from which varied elements may be selected. One of these issues, one that is proving to be a highly fruitful research avenue and constitutes the leitmotif of the present article, is the study of the hidden structures underlying an interactive situation such as a game of soccer. The approach here concerns the way in which temporal patterns are able to reveal those aspects of social interactions that are not immediately observable and considers that every interactive flow is governed by behavioral structures of varying stability that can be visualized by detecting hidden temporal patterns, such as T-patterns. These temporal patterns can be detected by means of the powerful algorithm of the THEME software, developed by Magnusson (1996, 2000), which imports data obtained by SOF-CODER. This constitutes the second aim of the present study.

The use of T-patterns and THEME has proven to be extraordinarily productive for the study of the many different aspects or fields of social interaction, as illustrated by research into team sport (Anguera \& Ardá, 2003; Anguera

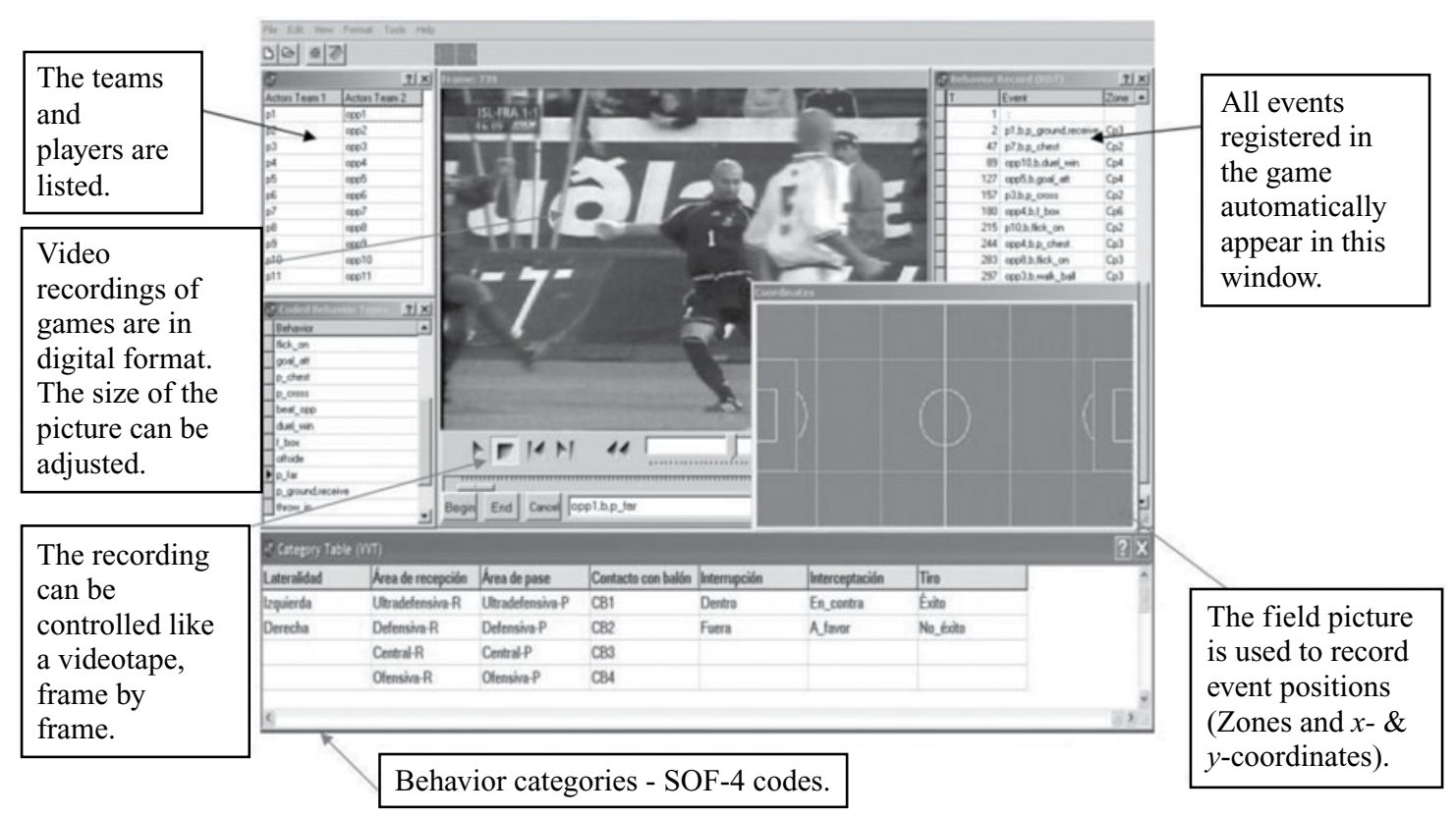

Figure 1. Screen capture of SportCoder using SOF-4 codes. 
Table 2

Fixed Criteria From the SOF-5

\begin{tabular}{|c|c|c|c|}
\hline & Level 1 & \multicolumn{2}{|l|}{ Level 2} \\
\hline \multirow[t]{7}{*}{ FIXED CRITERIA } & $\begin{array}{l}\text { Data .../.../... } \\
\text { Observed: } \\
\text { Opposite }\end{array}$ & & \\
\hline & Scope & $\begin{array}{l}\text { Soccer Club } \\
\text { National Team }\end{array}$ & $\begin{array}{l}\square \\
\square\end{array}$ \\
\hline & Tournament & $\begin{array}{l}\text { National } \\
\text { International }\end{array}$ & $\begin{array}{l}\square \\
\square\end{array}$ \\
\hline & Championship & $\begin{array}{l}\text { League } \\
\text { Cup } \\
\text { Friendly Match }\end{array}$ & $\begin{array}{l}\square \\
\square \\
\square\end{array}$ \\
\hline & Field & $\begin{array}{l}\text { Home } \\
\text { Away } \\
\text { Neutral }\end{array}$ & $\begin{array}{l}\square \\
\square \\
\square\end{array}$ \\
\hline & Time & $\begin{array}{l}\text { First Half } \\
\text { Second Half } \\
\text { Extra Time } 1 \\
\text { Extra Time } 2\end{array}$ & $\begin{array}{l}\square \\
\square \\
\square \\
\square\end{array}$ \\
\hline & Qualification & $\begin{array}{l}\text { League } \\
\text { Not Relevant }\end{array}$ & $\begin{array}{l}\square \\
\square\end{array}$ \\
\hline
\end{tabular}

\& Jonsson, 2002, 2003; Bloomfield et al., 2005; Borrie, Jonsson, \& Magnusson, 2001, 2002; Jonsson, Bjarkadottir, Gislason, Borrie, \& Magnusson, 2003).

\section{METHOD}

\section{Design}

The observational design (Anguera, Blanco-Villaseñor, \& Losada, 2001) is nomothetic (some matches), point (one match for each pair of teams and intrasession follow-up in each match), and multidimensional (these dimensions correspond with the criteria of the observational instrument).

A number of methodological decisions (structure of observation instrument, kind of data, control of quality of data, and data analysis) were made as a result of this N/P/M (nomothetic/point/multidimensional) design.

\section{Participants}

The present study is part of an ongoing and broader research project involving the analysis of all the games played by Barcelona Football Club (Spain) during the national League Championship and the Champions' League for several seasons. From these games, we have selected six specific matches, corresponding to Soccer League Division One, from the period 2000-2001, in order to apply the SOF-CODER instrument (see Table 1).

\section{Instruments}

The SOF-5 instrument. In order to achieve a systematized game analysis, an instrument combining field formats with systems of categories is proposed. The instrument is based on the continued development of the SOF instrument from Versions 1 to 4 (Anguera et al., 2000; Anguera et al., 2003; Anguera, Blanco-Villaseñor, et al., 2004).

The underlying approach of the SOF-5 instrument (Blanco-Villaseñor et al., 2006; Castellano, 2000) is based on fixed criteria (scope, tournament, championship, field, time, and qualification), mixed criteria (scoreboard and symmetry/asymmetry), and changing criteria (side, zone, play action, interaction contexts, and action time). Each one of these gives rise to a system of categories that are exhaustive and mutually exclusive.

The system records the type of competition, the stadium where it is played, and the number and order of play actions for each of the two teams, the purpose being to develop a comprehensive database covering different (complete) seasons and different teams.

The structure of the instrument was developed to complement the field format and system of categories, thus ensuring that they are consistent with a multidimensional profile (in terms of the number of criteria proposed in each case) and that each of the dimensions gives rise either to a system of categories (exhaustive and mutually exclusive) or to a list of traits in those cases in which the basic conditions inherent within a system of categories could not be met.

A coding manual containing definitions of all the categories, worked examples, and the syntactic rules that govern and normalize their use has been developed for the instrument (Blanco-Villaseñor et al., 2006).

The SOF-CODER as both an observation and a recording instrument. The SOF-CODER system enables the user to transcribe a match on a computer (Jonsson, 2006). The categorization and coding processes use digital technology that allows analog audiovisual information to be converted into digital video by means of frames $(1 / 25 \mathrm{sec})$, thus greatly increasing the degree of accuracy obtained.

Table 3

Mixed Criteria From the SOF-5

\begin{tabular}{|l|l|l|l|l|}
\hline & Level 1 & Level 2 & Level 3 & Level 4 \\
\hline \multirow{3}{*}{$\begin{array}{l}\text { MIXED } \\
\text { CRITERIA }\end{array}$} & Scoreboard & & & $\begin{array}{l}\text { Accumulated } \\
\text { Scoreboard }\end{array}$ \\
\cline { 3 - 5 } & & Won & 1 & Won \\
\cline { 3 - 5 } & & Draw & & Draw \\
\cline { 3 - 5 } & & Lost & -1 & Lost \\
\cline { 3 - 5 } & & & & \\
\cline { 3 - 5 } & Symmetry/Asymmetry & & & \\
\hline
\end{tabular}


Table 4

Changing Criteria From the SOF-5

\begin{tabular}{|c|c|c|c|c|}
\hline \multirow{3}{*}{\begin{tabular}{|l|} 
\\
CHANGING \\
CRITERIA
\end{tabular}} & \multirow{3}{*}{\begin{tabular}{|l} 
Level 1 \\
Side
\end{tabular}} & \\
\hline & & \multirow{2}{*}{\begin{tabular}{|l|} 
Level 2 \\
Right \\
Central \\
Left
\end{tabular}} & \multirow[t]{2}{*}{ Level 3} & \multirow[t]{2}{*}{ Level 4} \\
\hline & & & & \\
\hline & Zone & $\begin{array}{l}\text { Ultra-defensive } \\
\text { Defensive } \\
\text { Central } \\
\text { Offensive } \\
\text { Ultra-offensive } \\
\end{array}$ & & \\
\hline & \multirow[t]{5}{*}{ Play Action } & \multirow[t]{2}{*}{ Start (in favor) } & Stopped Ball & $\begin{array}{l}\text { Inside Player (fail) } \\
\text { Outside Player (corner, to kick off goal) } \\
\text { Outside Throw-In }\end{array}$ \\
\hline & & & Ball Motion & Retrieval \\
\hline & & \multirow[t]{3}{*}{ End } & $\begin{array}{l}\text { Stopped Ball } \\
\text { (in favor) }\end{array}$ & $\begin{array}{l}\text { Inside Player (fail) } \\
\text { Outside Player (corner, to kick off goal) } \\
\text { Outside Throw-In Goal }\end{array}$ \\
\hline & & & $\begin{array}{l}\text { Stopped Ball } \\
\text { (against) }\end{array}$ & $\begin{array}{l}\text { Inside Player (fail) } \\
\text { Outside Player (corner, to kick off goal) } \\
\text { Outside Throw-In Goal }\end{array}$ \\
\hline & & & Ball Motion & Loss \\
\hline & $\begin{array}{l}\text { Interaction } \\
\text { Contexts }\end{array}$ & \begin{tabular}{|l|} 
RM \\
RA \\
MR \\
MM \\
MA \\
AR \\
AM \\
AO \\
AO \\
OO
\end{tabular} & & \\
\hline & \begin{tabular}{|l|} 
Action \\
Time
\end{tabular} & & & \\
\hline
\end{tabular}

Coding, a relatively complex operation that can be planned on the basis of a wide range of codes (literal, numerical, mixed, iconic, chromatic, etc.), involves making decisions after having taken into account the advantages and disadvantages of each of these codes with respect to the situation under study. The use of an interactive multimedia computer program facilitates the collection of timebased data from digitized video files. This gives access to the duration and sequence of each action and a fragment of the observation sessions.

There are several software packages available that meet these requirements - for example, Codex (HernándezMendo, Anguera, \& Bermúdez, 2000), SportCoder (Anguera \& Jonsson, 2003) and Match Vision Studio (Perea, Alday, \& Castellano, 2004) - that are particularly suitable for recording sport events. However, further developments have been necessary in this area, and work is currently underway on normalizing the use of specific software in order to control reliability, accuracy, and validity of the field format categories or codes that will have been previously coded and recorded digitally.

Adapting the SportCoder to SOF-CODER. The first step in the development of the SOF-CODER system was to import the SOF-4 codes into a previously existing tool, SportCoder (Anguera \& Jonsson, 2003). The multimedia system developed on the basis of Theme Coder (previously a part of the Theme software) was designed for the collection of time-based data in sport (see Figure 1) and enabled users to develop their own system of categories for the data collection procedure.

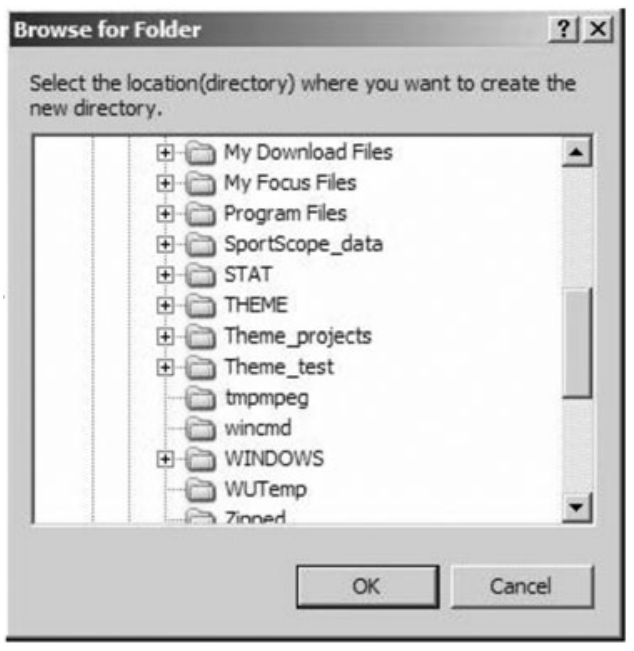

Figure 2. Selecting the location where the project files will be stored. 


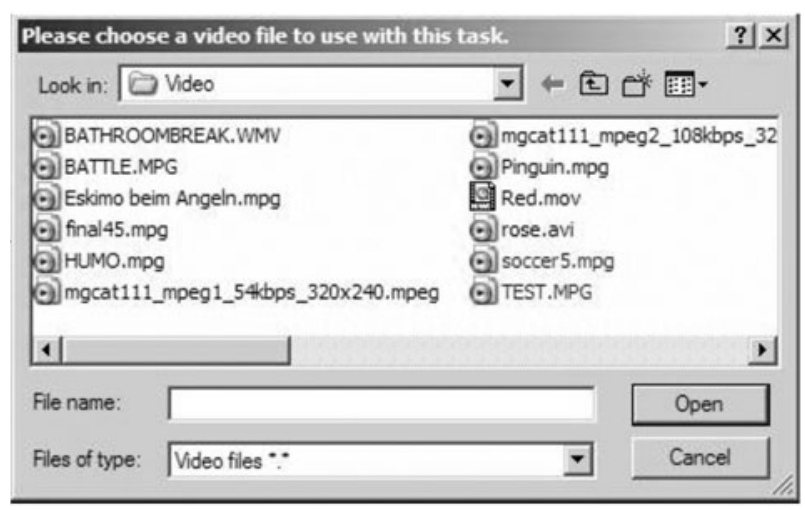

Figure 3. Selecting the digitized video file that will be analyzed.

Preliminary research using the SOF-4 and SOF-5 codes and continued development of the SOF instruments (see Anguera, Blanco-Villaseñor, et al., 2003; Anguera, Blanco-Villaseñor, et al., 2004), focusing on different methodological and statistical issues, as well as on elements of the game, resulted in a comprehensive platform for the development of the current SOF-CODER. The fixed criteria implemented in the SOF-CODER (see Table 2) list two levels of background variables concerning, for example, type of tournament and field of the game to be analyzed.

The mixed criteria of the SOF-CODER (see Table 3) enable collection of data concerning the accumulating scoreboard, as well as symmetry/asymmetry issues of the game.

The changing criteria of the SOF-CODER (see Table 4) comprise several levels of analysis, ranging from side, zone, and action time to ball motion and different levels of play action.

Basic procedures using the SOF-CODER. The basic use of the SOF-CODER system (Jonsson, 2006) consists of the following steps.

1. The program is started.

2. The location where the project files will be stored is selected (see Figure 2).

3. The digitized video file to be analyzed in the current project is selected (see Figure 3).

4. Relevant items in the list of criteria are marked (see Table 2).

5. Once the project folder and digitized video file have been selected and the relevant criteria marked, the SOF-CODER interface opens automatically (see Figure 4), and the user can start transcribing the match to be analyzed.

6. When transcribing the match, the user will stop the image at the appropriate time, using the video control functions (see the image box in Figure 4), and select an actor/team (see the upper left corner in Figure 4) and relevant categories (see the Changing Criteria box at the bottom of Figure 4). The selection will automatically prompt the coordinate (pitch) window, where the user can click on the image (see the coordinate window in Figure 4) and place the action on the pitch, collecting information on

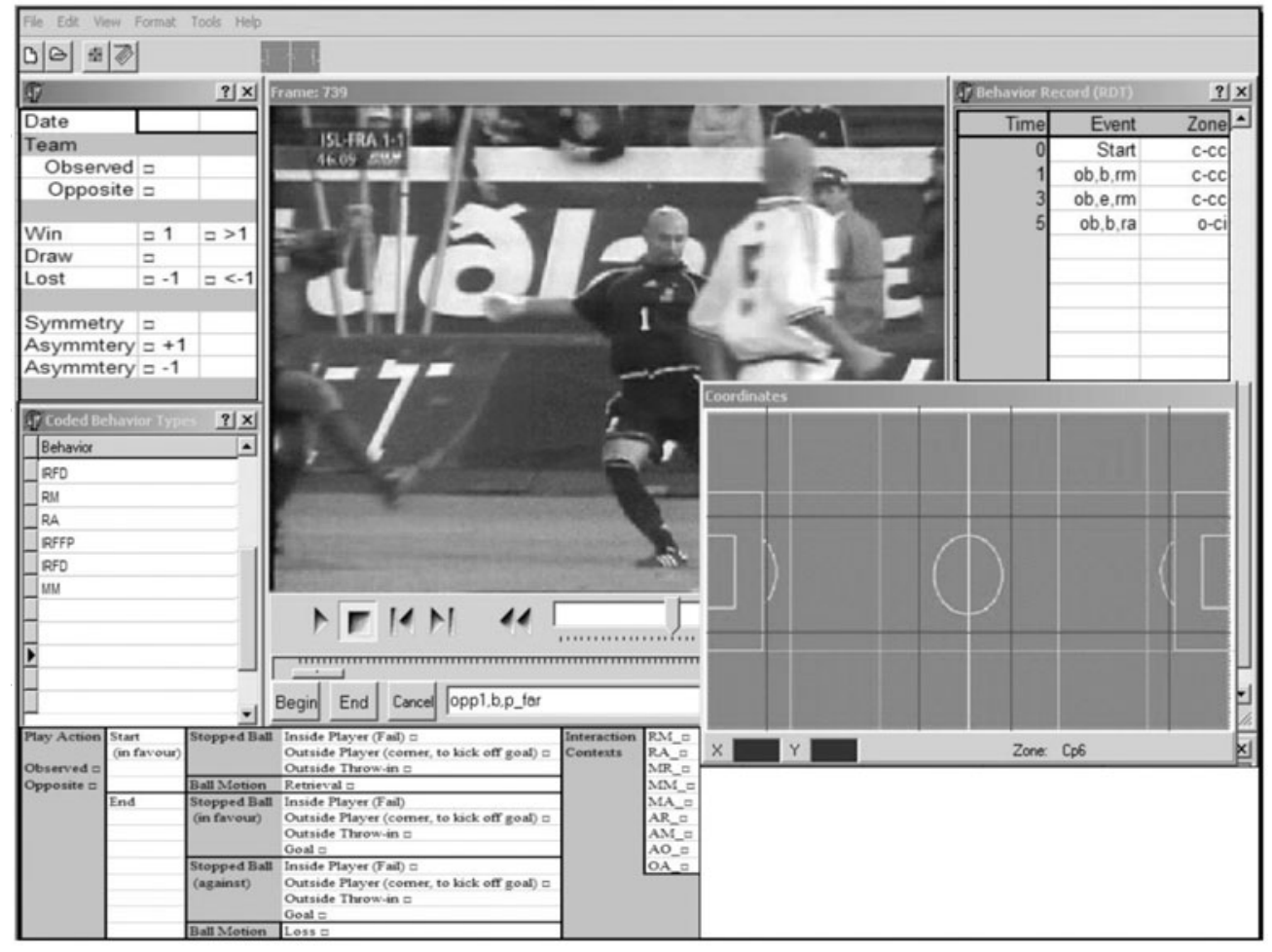

Figure 4. The SOF-CODER interface. 
Table 5

Fragment of a Data File (CSV Format)

\begin{tabular}{lrl}
\hline \multicolumn{1}{c}{ DATANAME } & \multicolumn{1}{c}{ T } & \multicolumn{1}{c}{ Events } \\
\hline FCB-BETIS_FIRST & 1 & : \\
FCB-BETIS_FIRST & 375 & CE,UD,IR,RA \\
FCB-BETIS_FIRST & 650 & CE,UD,FT,RA \\
FCB-BETIS_FIRST & 700 & CE,C,MM \\
FCB-BETIS_FIRST & 850 & CE,O,MM \\
FCB-BETIS_FIRST & 1125 & CE,O,IFFM,OO \\
FCB-BETIS_FIRST & 1425 & CE,UO,AR \\
FCB-BETIS_FIRST & 1500 & IZ,O,AR \\
FCB-BETIS_FIRST & 1675 & IZ,C,FP,MM \\
FCB-BETIS_FIRST & 1900 & IZ,UD,IR,RA \\
FCB-BETIS_FIRST & 2025 & CE,O,RM \\
FCB-BETIS_FIRST & 2075 & CE,D,MM \\
FCB-BETIS_FIRST & 2200 & CE,O,FP,MR \\
FCB-BETIS_FIRST & 2275 & IZ,C,IR,MM \\
FCB-BETIS_FIRST & 2450 & CE,C,MM \\
FCB-BETIS_FIRST & 2550 & IZ,O,MR \\
FCB-BETIS_FIRST & 2650 & IZ,O,FP,MR \\
FCB-BETIS_FIRST & 2775 & IZ,O,IFFM,MM \\
FCB-BETIS_FIRST & 2900 & CE,C,MM \\
FCB-BETIS_FIRST & 3150 & IZ,UO,FP,AR \\
FCB-BETIS_FIRST & 3525 & IZ,O,IFFM,AR \\
FCB-BETIS_FIRST & 3700 & CE,C,RM \\
FCB-BETIS_FIRST & 3775 & CE,C,MM \\
\hline
\end{tabular}

both the zone where the activity took place and the $x$ - and $y$ coordinates. All information is automatically stored in the cumulative Behavior Record (see the box in the upper right corner in Figure 4), with the exact time of occurrence.

\section{Procedure}

Observational records were obtained using SOF-CODER. The record of six matches consists of 3,134 data rows.

The resulting data files contain a $T$ column (with the temporal frames) and, for the different codes, an Events column (see a sample in Table 5).

The data are then imported into the Theme software in order to detect hidden patterns. Figure 5 shows a fragment of a data file after importing into Theme.

The codes of the SOF-5 observational instrument included in SOF-CODER are prepared in a VVT file. The criteria of the instrument are sorted as columns, and the respective codes of each one as rows. Figure 6 shows these codes as viewed in the Theme software.

The Theme software (see www.patternvision.com) enables complex repeated temporal patterns to be detected even when a large number of unrelated events occur in between components of the patterns, which typically makes them invisible to the naked eye (Magnusson, 1996, 2000). The basic assumption is that the temporal structure of a complex behavioral system is largely unknown but may involve a set of a particular type of repeated temporal patterns (T-patterns) composed of distinguishable event types, which are coded in terms of their beginning and end points (such as player begins passing the ball or player ends running up right wing). The kind of behavior record (as a set of time point series or occurrence time series) that results from such coding of behavior within a particular observa-

\begin{tabular}{|c|c|c|c|c|c|c|c|c|}
\hline \multicolumn{9}{|c|}{$\begin{array}{l}\text { P. Theme-FCB_ALL,tpf } \\
\text { File Edit Project View Search }\end{array}$} \\
\hline \multicolumn{9}{|c|}{ 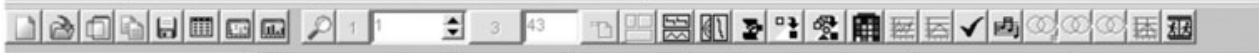 } \\
\hline DATANAME & DataName & Time & Evert & LATERALITY & ZONE & INTLAL_POSSESSION & END_POSSESSION & INTERACTION_CONTEXT \\
\hline athletic-bilbao_fcb_ & D_fcb_betis_first & 15 & $:$ & & & & & \\
\hline athletic-bilbao_fcb_ & ficb_betis_first & 375 & udir ra & & ud & ir & & ra \\
\hline tcb_betis_first & fcb_betis_first & 650 & ce,ud,ir,ftya & ce & ud & ir & $\pi$ & ra \\
\hline icb_betis_second & fcb_betis_first & 700 & ce,c,mm & ce & c & & & $\mathrm{mm}$ \\
\hline fcb_deportivo_first & tcb_betis_first & 1125 & $c e, 0, j \mathrm{itm}, 00$ & ce & 0 & iffm & & $\infty$ \\
\hline fcb_deportivo_second & ficb_betis_first & 1250 & ce,o,mm & ce & $\circ$ & & & $\mathrm{men}$ \\
\hline fcb_racing_first & fcb_betis_first & 1425 & ce,uo,ar & ce & uo & & & ar \\
\hline fcb_racing_second & ficb_betis_first & 1500 & $i z, 0, a x$ & $i z$ & 0 & & & ar \\
\hline las_painas_fcb_first & tcb_betis_first & 1675 & $i z, c, f p, m n$ & iz & c & & tp & $\mathrm{mm}$ \\
\hline las_palmas_fcb_secon & fcb_betis_first & 1850 & $i z, u d, j, r a$ & iz & ud & ir & & ra \\
\hline numancia_fcb_first & fcb_betis_first & 2025 & ce,orm & $c e$ & 0 & & & $\mathrm{~m}$ \\
\hline \multirow[t]{19}{*}{ numancia_tcb_second } & fcb_betis_first & 2075 & $c e, d, m m$ & $\mathrm{ce}$ & d & & & $\mathrm{mm}$ \\
\hline & fcb_betis_first & 2200 & $c e, 0, f p, m r$ & ce & $\circ$ & & $\mathrm{tp}$ & $\mathrm{mr}$ \\
\hline & fcb_betis_first & 2275 & iz,cirmm & iz & c & ir & & $\mathrm{men}$ \\
\hline & fcb_betis_first & 2450 & ce,c,mm & $c e$ & c & & & $\mathrm{mm}$ \\
\hline & tcb_betis_first & 2550 & $\mathrm{iz}, 0 \mathrm{mr}$ & iz & 0 & & & $\mathrm{mr}$ \\
\hline & fcb_betis_first & 2650 & $i z, \mathrm{fp}, \mathrm{mr}$ & iz & & & $t p$ & $\mathrm{mr}$ \\
\hline & tcb_betis_first & 2775 & $i z, 0, j f t m, m m$ & iz & $\circ$ & iftm & & $\mathrm{mm}$ \\
\hline & fcb_betis_first & 2900 & $\mathrm{ce}, \mathrm{c}, \mathrm{mm}$ & ce & c & & & $\mathrm{mm}$ \\
\hline & Ttcb_betis_first & 3150 & $i z, 40$, tp, ar & iz & uo & & tp & ar \\
\hline & fcb_betis_first & 3525 & iz,o,jftm,ar & iz & 0 & iftm & & ar \\
\hline & fcb_betis_first & 3700 & ce,c,rm & ce & c & & & $\mathrm{mm}$ \\
\hline & fcb_betis_first & 3775 & ce, $\mathrm{nm}$ & ce & & & & $\mathrm{mm}$ \\
\hline & fcb_betis_first & 3800 & ce,c, mm & ce & c & & & $\mathrm{mm}$ \\
\hline & icb_betis_first & 3925 & ce,c,tctp, mm & ce & c & & tetp & $\mathrm{mm}$ \\
\hline & tcb_betis_first & 4600 & $i z, d, i r, m$ & iz & d & ir & & $\mathrm{m}$ \\
\hline & fcb_betis_first & 4850 & $i z, d, j f t m, m$ & $i z$ & d & iftm & & $\mathrm{m}$ \\
\hline & tcb_betis_first & 4950 & $c e, d r a$ & ce & d & & & ra \\
\hline & tcb_betis_first & 5150 & $i z, c, m m$ & iz & c & & & $\mathrm{mm}$ \\
\hline & tcb_betis_first & 5225 & iz, 0, tp,ar & iz & 0 & & tp & ar \\
\hline
\end{tabular}

Figure 5. Data file from SOF-CODER imported into the Theme software. 


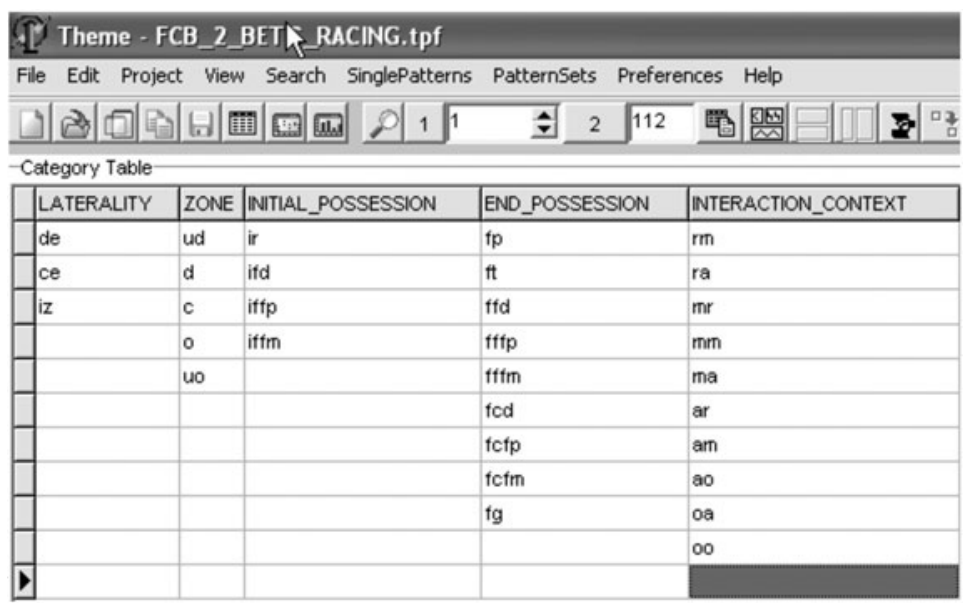

Figure 6. Codes of the observational instrument SOF-5 displayed in Theme.

tion period (here, called T-data) constitutes the input to the T-pattern definition and detection algorithms. Essentially, within a given observation period, if two actions, A and $\mathrm{B}$, occur repeatedly in that order or concurrently, they are said to form a T-pattern (AB) if they are found more often than would be expected by chance; assuming as $h_{0}$ an independent distribution for $\mathrm{A}$ and $\mathrm{B}$, there is approximately the same time distance (called the critical interval, $\mathrm{CI})$ between them. Instances of A and B related by that approximate distance then constitute occurrence of the $(\mathrm{AB})$ T-pattern, and its occurrence times are added to the original data. More complex T-patterns are gradually detected as patterns of simpler already-detected patterns through a hierarchical bottom-up detection procedure (Magnusson, 1996, 2000). The pattern in Figure 7 illustrates how a larger pattern $((\mathrm{AB})(\mathrm{CD}))$ is detected as a combination of the two simpler patterns $(\mathrm{AB})$ and $(\mathrm{CD})$. Even in data sets of moderate size, the number of potential T-patterns is very high. Special algorithms deal with potential combinatorial explosions due to redundant and partial detection of the same patterns, using an evolution algorithm (completeness competition) that compares all the detected patterns and lets only the most complete patterns survive. Since any basic time unit may be used, T-patterns are, in principle, scale independent, although only a limited range of basic unit size is relevant in each specific study.

\section{RESULTS}

Once users have finished transcribing the game, they can visualize different basic statistical information based on the game's criteria. This includes frequency counts of match events (see Figure 8) and the frequency and duration of game events (see Figure 9).

In order to control the quality of data (BlancoVillaseñor, 1993; Blanco-Villaseñor \& Anguera, 2000; Jansen, Wiertz, Meyer, \& Noldus, 2003), the kappa coefficient has been calculated (.82 for all matches).

During the process of transcribing the game, the SOF-CODER automatically accumulates the data file that can be exported for more detailed analysis - for example, pattern detection and analysis with the Theme software (Borrie, Jonsson, \& Magnusson, 2001, 2002; Magnusson, 1996, 2000).

An analysis of transcribed records revealed a high number of repeated complex temporal structures within the game events of the particular match analyzed. For the pattern detection, the following search criteria were used: minimum number of occurrences, set at 3 ; significance level at .005; and other criteria as default. In line with previous studies in this area, the data show that soccer contains a large number of temporal patterns. The number, frequency, and complexity of the detected patterns indicate that sport behavior is

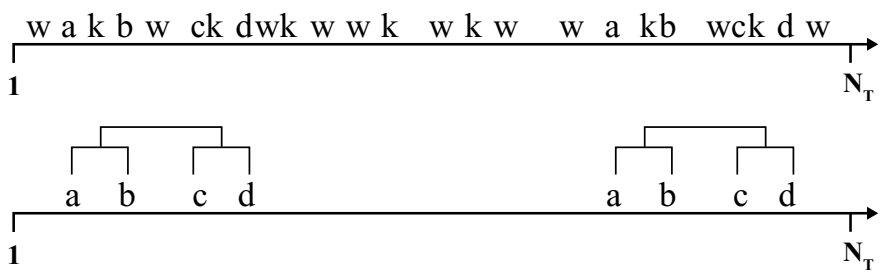

Figure 7. Example of a repeated T-pattern: The figure illustrates how a larger pattern $((\mathrm{AB})(\mathrm{CD}))$ is detected as a combination of the two simpler patterns $(A B)$ and $(C D)$. 


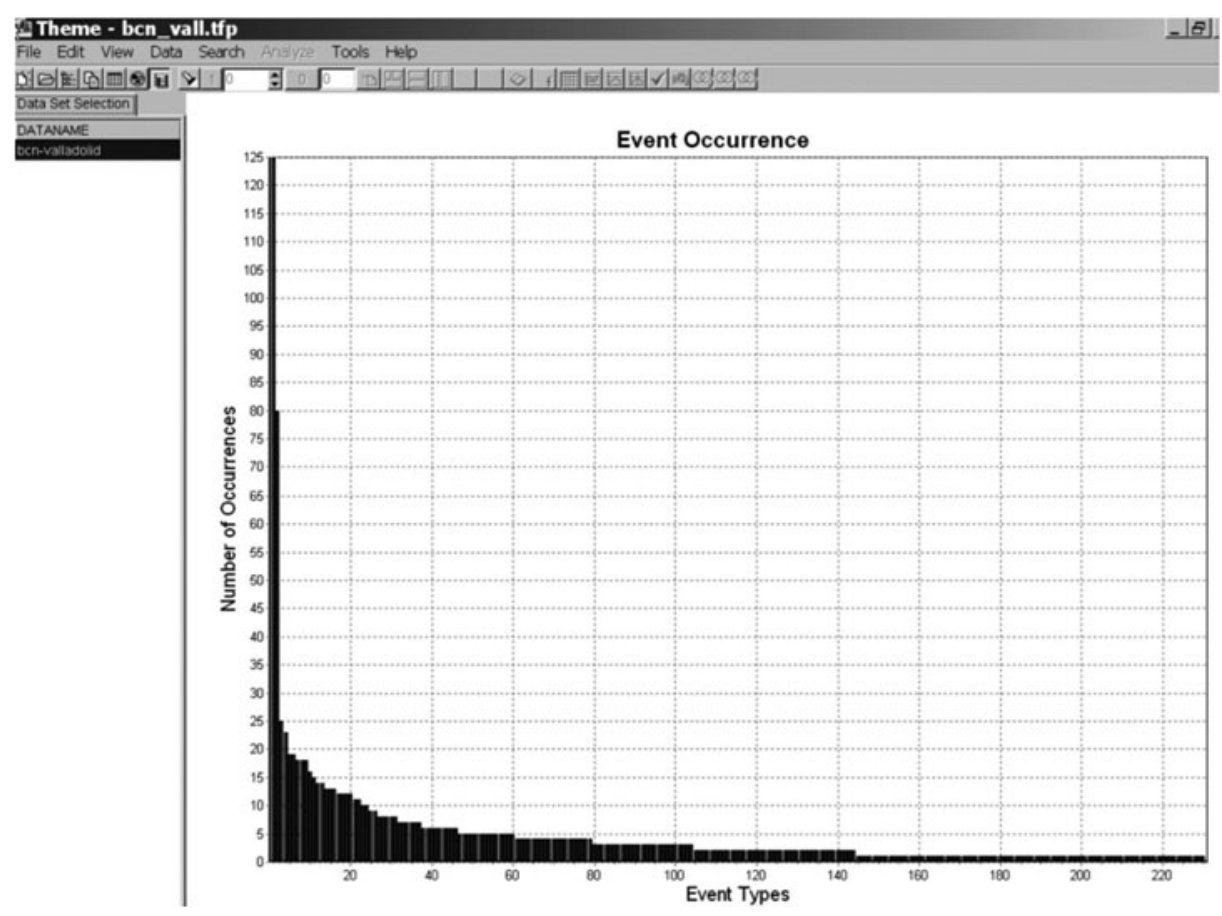

Figure 8. Event frequency chart.

much more synchronized than the human eye can detect. This synchrony was found to exist on different levels, with highly complex time structures extending over considerable time spans within performances and with patterns occurring in both cyclical and acyclical fashions (Anguera, Jonsson, Magnusson, Losada, \& Blanco-Villaseñor, 2004). For instance, 21 different T-patterns were detected in one of the games analyzed, an example being shown in Figure 10.

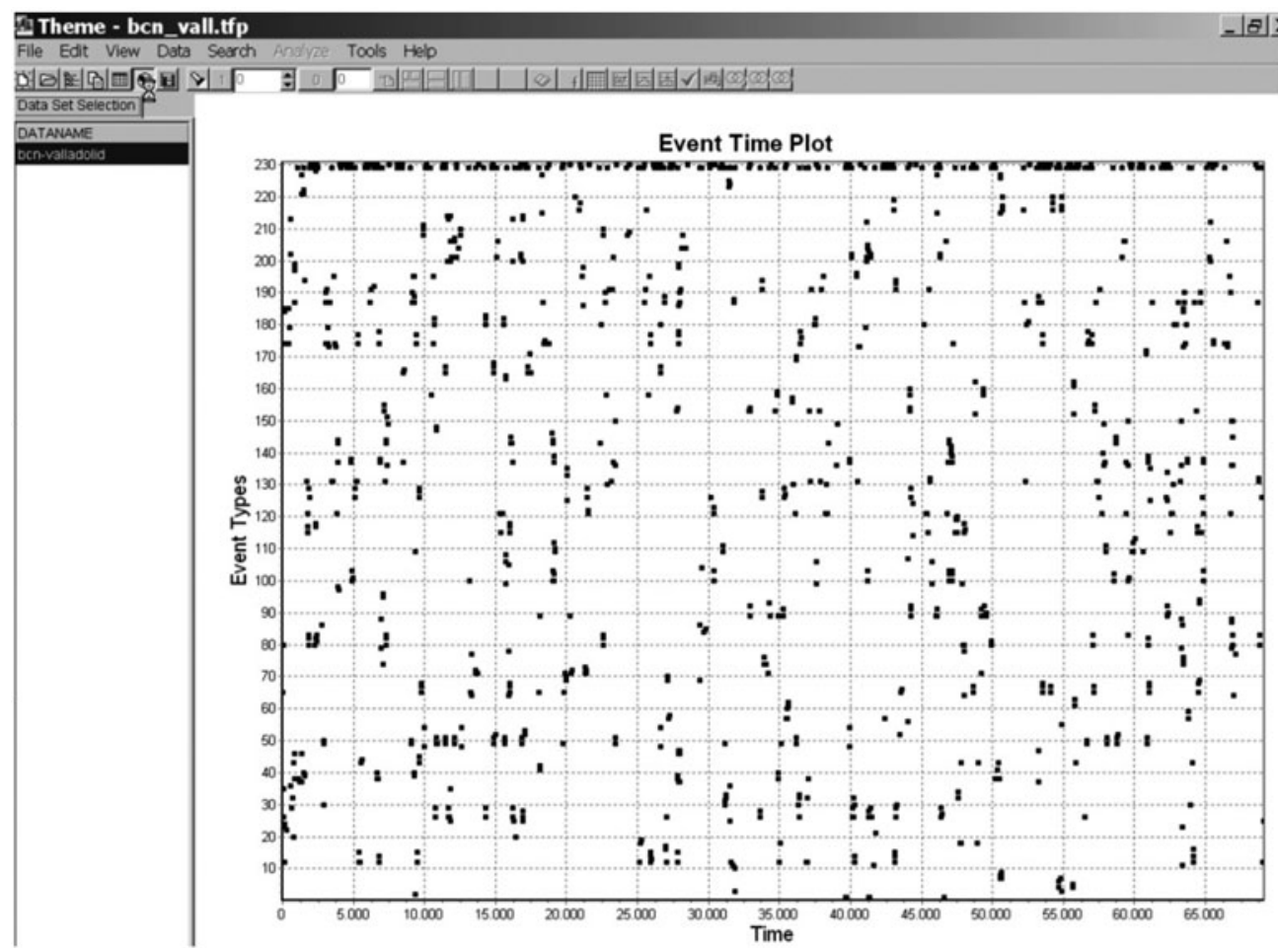

Figure 9. Event time plot. 


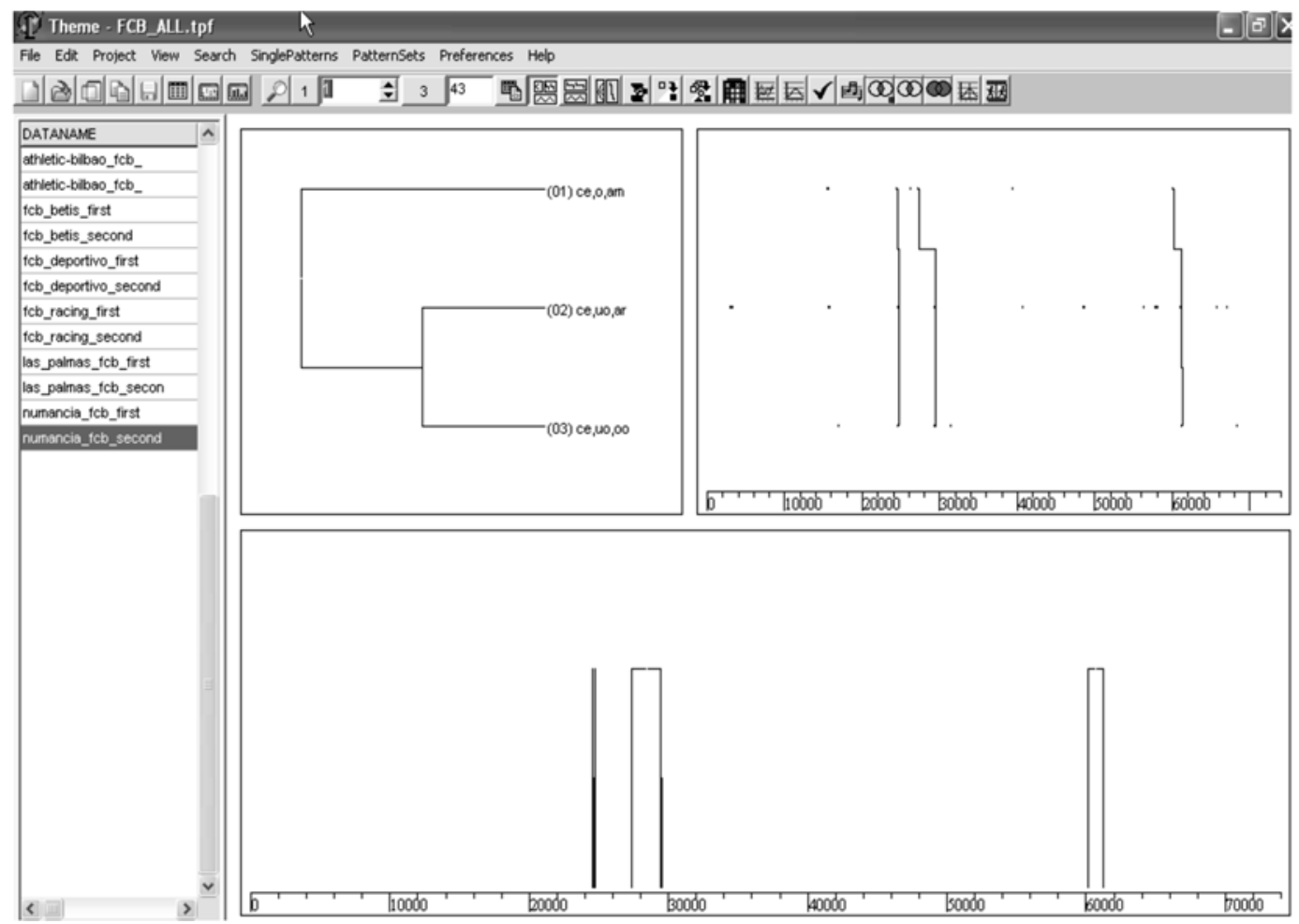

Figure 10. An example of a detected T-pattern.

The pattern represented in Figure 10 occurred three times during the first half of the match, with a duration of 3,378 frames ( $5 \%$ of the observation period), and describes the following sequence of action: There is an alternation between the location of the ball in an offensive and ultraoffensive zone, and the interaction between both teams implies the successive situations of advanced medium, advanced delayed, and situations in which the ball is stopped because there has been a prescribed interruption.

\section{DISCUSSION}

The SOF-CODER is a powerful tool that can be used as both an observation and a recording instrument. As an observation instrument, it can be adapted to the best possibilities in each case (now the SOF-5) and modified to suit the team sport in question. As a recording instrument, the SOF-CODER has a number of advantages, such as the use of digitized video, frame as the time unit, use of the mouse in order to avoid making errors and for correcting them, and the ability to export the data file in standard Excel format. Moreover, as has already been mentioned, the SOF-CODER files can be directly imported into Theme for the detection and analysis of complex hidden patterns of play.

Given the above, the authors conclude that the use of the current observational design and T-pattern detection in soccer shows tremendous potential. The identification of patterns that are not identifiable through simple observation is of great benefit, not only in match-play, but also in establishing the physical demands through time-motion analysis. The selected example concerns a critical action that has begun in an offensive zone and advanced position of one team (with the opposing team in an intermediate position), followed by a player of the same team, in an ultraoffensive zone and an advanced position (with a delayed position of the opposing team), committing a foul; thus, the ball is stopped, and there is no interaction context.

The preliminary data shown highlight the potential of the current design and analysis to move beyond the constraints of traditional frequency-based analyses of performance and make a significant contribution to a deeper understanding of sports performance. The results suggest that there is a very real possibility of discovering new kinds of profiles (complex intra- and interindividual patterns), using the detected behavioral patterns in combination with elementary statistics. Without this form of analysis, important information may be overlooked and, thus, opportunities missed for the optimization of performance.

\section{REFERENCES}

Anguera, M. T. (2003). Observational methods (general). In R. FernándezBallesteros (Ed.), Encyclopedia of psychological assessment (Vol. 2, pp. 632-637). London: Sage.

Anguera, M. T. (2005). Microanalysis of T-patterns: Analysis of 
symmetry/asymmetry in social interaction. In L. Anolli, S. Duncan, M. Magnusson, \& G. Riva (Eds.), The hidden structure of social interaction: From genomics to culture patterns (pp. 51-70). Amsterdam: IOS Press.

ANGUERA, M. T., \& ARDÁ, T. (2003, August). Hidden patterns in seven-aside football: How do children interact during play? Paper presented at the XI European Conference on Developmental Psychology, Milan.

Anguera, M. T., Blanco-Villaseñor, A., \& Losada, J. L. (2001). Diseños observacionales, cuestión clave en el proceso de la metodología observacional. Metodología de las Ciencias del Comportamiento, $\mathbf{3}$, 135-161.

Anguera, M. T., Blanco-Villaseñor, A., Losada, J. L., Ardá, T., Camerino, O., Castellano, J., \& Hernández-Mendo, A. (2000). Instrumento de codificación y registro de la acción de juego en fútbol (SOF-1). Revista Digital de Alto Rendimiento en Fútbol (Universidad de Extremadura).

Anguera, M. T., Blanco-Villaseñor, A., Losada, J. L., Ardá, T., Camerino, O., Castellano, J., et al. (2003). Match and player analysis in soccer: Computer coding and analytic possibilities. International Journal of Computer Science in Sport (e-journal), 2, 118-121.

Anguera, M. T., Blanco-Villaseñor, A., Losada, J. L., Ardá, T., Camerino, O., Castellano, J., et al. (2004, March). SOF-4: Instrumento de registro y codificación en el fútbol. Multimedia presentation at the II Congreso Internacional de Actualización en Psicología del Deporte. Buenos Aires.

Anguera, M. T., \& Jonsson, G. K. (2002, June). Detection of realtime patterns in sports: Interactions in football. Paper presented at the Third Meeting of the European Research Group on Methodology for the Analysis of Social Interaction, Milan.

Anguera, M. T., \& Jonsson, G. K. (2003). Detection of real-time patterns in sport: Interactions in football. International Journal of Computer Science in Sport (e-journal), 2, 118-121.

Anguera, M. T., Jonsson, G. K., Magnusson, M., Losada, J. L., \& Blanco-VIllaseñor, A. (2004, June). Variability of temporal patterns intra-team and between teams in football. Paper presented at the Fourth Meeting of European Research Group on Methodology for the Analysis of Social Interaction, Barcelona.

Blanco-VILlaseñor, A. (1993). Fiabilidad, precisión, validez y generalización de los diseños observacionales. In M. T. Anguera (Ed.), Metodología observacional en la investigación psicológica (Vol. 2, pp. 149-261). Barcelona: P.P.U.

Blanco-Villaseñor, A., \& Anguera, M. T. (2000). Evaluación de la calidad en el registro del comportamiento: Aplicación a deportes de equipo. In E. Oñate, F. García-Sicilia, \& L. Ramallo (Eds.), Métodos numéricos en ciencias sociales (pp. 30-48). Barcelona: Centro Internacional de Métodos Numéricos en Ingeniería.

Blanco-Villaseñor, A., Castellano, J., Hernández-Mendo, A., Anguera, M. T., Losada, J. L., Ardá, A., \& Camerino, O. (2006). Observación y registro de la interacción en el fútbol. In J. Castellano, L. M. Sautu, A. Hernández-Mendo, A. Blanco-Villaseñor, A. Goñi, \&
F. Martínez (Eds.), Socialización y deporte: Revisión crítica. VitoriaGasteiz, Spain: Diputación Foral de Álava/Arabako Foru Aldundia.

Bloomfield, J., Jonsson, G. K., Polman, R., Houlahan, K., \& O'Donoghue, P. (2005). Temporal patterns analysis and its applicability in soccer. In L. Anolli, S. Duncan, M. Magnusson, \& G. Riva (Eds.), The hidden structure of social interaction: From genomics to culture patterns (pp. 237-251). Amsterdam: IOS Press.

Borrie, A., Jonsson, G. K., \& Magnusson, M. S. (2001). Application of T-pattern detection and analysis in sports research. Metodología de las Ciencias del Comportamiento, 3, 215-226.

Borrie, A., Jonsson, G. K., \& Magnusson, M. S. (2002). Temporal pattern analysis and its applicability in sport: An explanation and exemplar data. Journal of Sports Sciences, 20, 845-852.

Carletta, J., Evert, S., Heid, U., Kilgour, J., Robertson, J., \& Voormann, H. (2003). The NITE XML Toolkit: Flexible annotation for multimodal language data. Behavior Research Methods, Instruments, \& Computers, 35, 353-363.

Castellano, J. (2000). Observación y análisis de la acción de juego en el fútbol. Unpublished doctoral thesis, Universidad del País Vasco, Vitoria, Spain.

Hernández-Mendo, A., Anguera, M. T., \& Bermúdez Rivera, M. A. (2000). Software for recording observational files. Behavior Research Methods, Instruments, \& Computers, 32, 436-445.

Jansen, R. G., Wiertz, L. F., Meyer, E. S., \& Noldus, L. P. J. J. (2003). Reliability analysis of observational data: Problems, solutions, and software implementation. Behavior Research Methods, Instruments, \& Computers, 35, 391-399.

JonsSON, G. K. (2006). SOF-CODER: Technological and multimedia system for recording data in soccer. In J. Castellano, L. M. Sautu, A. Hernández-Mendo, A. Blanco-Villaseñor, A. Goñi, \& F. Martínez (Eds.), Socialización y deporte: Revisión crítica. Vitoria-Gasteiz, Spain: Diputación Foral de Álava/Arabako Foru Aldundia.

Jonsson, G. K., Buarkadottir, S. H., Gislason, B., Borrie, A., \& Magnusson, M. S. (2003). Detection of real-time patterns in sports: Interactions in football. In C. Baudoin (Ed.), L'éthologie appliquée aujourd'hui: Vol. 3. Ethologie humaine (pp. 37-46). Levallois-Perret, France: Editions ED.

Magnusson, M. S. (1996). Hidden real-time patterns in intra- and interindividual behavior. European Journal of Psychological Assessment, 12, 112-123.

Magnusson, M. S. (2000). Discovering hidden time patterns in behavior: T-patterns and their detection. Behavior Research Methods, Instruments, \& Computers, 32, 93-110.

Perea, A., Alday, L., \& Castellano, J. (2004, November). Software para la observación deportiva Match Vision Studio. Communication presented at the III Congreso Vasco del Deporte, Vitoria.

(Manuscript received September 29, 2005; revision accepted for publication February 28,2006 .) 